\title{
CORRECTION
}

\section{Correction to: Lung ultrasound predicts clinical course and outcomes in COVID-19 patients}

Yael Lichter ${ }^{1}$, Yan Topilsky¹, Philippe Taieb ${ }^{1}$, Ariel Banai ${ }^{1}$, Aviram Hochstadt ${ }^{1}$, Ilan Merdler ${ }^{1}$, Amir Gal Oz'

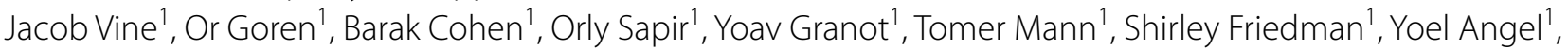
Nimrod Adi ${ }^{1}$, Michal Laufer-Perl ${ }^{1}$, Merav Ingbir ${ }^{1}$, Yaron Arbel ${ }^{1}$, Idit Matot ${ }^{1}$ and Yishay Szekely ${ }^{1,2^{*}}$ (D)

(ㄱ) 2020 Springer-Verlag GmbH Germany, part of Springer Nature

\section{Correction to: Intensive Care Med}

https://doi.org/10.1007/s00134-020-06212-1

The original version of this article unfortunately contained a mistake. There was an error in Table 2. The correct Table 2 can be found below. The original article was updated. We apologize for the mistake.

\section{Springer}


Table 2 Patients stratified by clinical presentation at baseline lung ultrasound

\begin{tabular}{|c|c|c|c|c|}
\hline \multirow{2}{*}{ Parameter } & \multicolumn{3}{|c|}{ Clinical grade $^{a}$} & \multirow[t]{2}{*}{$p$ value } \\
\hline & $\begin{array}{l}\text { Mild } \\
n=75\end{array}$ & $\begin{array}{l}\text { Moderate } \\
n=31\end{array}$ & $\begin{array}{l}\text { Severe } \\
n=14\end{array}$ & \\
\hline Age, years, mean $\pm S D$ & $64.2 \pm 21$ & $72.3 \pm 13$ & $72.5 \pm 24$ & 0.12 \\
\hline Male gender, $n(\%)$ & $43(57)$ & $21(67)$ & $10(71)$ & 0.43 \\
\hline Modified early warning score, median (IQR) & $3(1-4)$ & $7(6-10)$ & $13(9-16)$ & $<0.0001$ \\
\hline Temperature, ${ }^{\circ} \mathrm{C}$, mean $\pm S D$ & $37.1 \pm 0.7$ & $37.4 \pm 0.8$ & $37.8 \pm 1.3$ & 0.02 \\
\hline $\mathrm{O}_{2}$ saturation, $\%$, mean $\pm \mathrm{SD}$ & $96.2 \pm 3$ & $88.7 \pm 6$ & $86.0 \pm 7$ & $<0.0001$ \\
\hline Heart rate, beats/min, mean $\pm S D$ & $81.1 \pm 15$ & $85.2 \pm 17$ & $98.2 \pm 20$ & 0.005 \\
\hline Pressor requirement, $n(\%)$ & $0(0)$ & $0(0)$ & $2(13)$ & 0.02 \\
\hline C-reactive protein, $\mathrm{mg} / \mathrm{L}$, mean $\pm \mathrm{SD}$ & $49.2 \pm 45$ & $106 \pm 65$ & $162.3 \pm 68$ & $<0.0001$ \\
\hline D-Dimer, mg/L, median (IQR) & $0.7(0.3-1.1)$ & $1.1(0.7-1.7)$ & $2.5(1.8-3.8)$ & $<0.0001$ \\
\hline Troponin-I, ng/L, median (IQR) & $8(4-18)$ & $14(7-31)$ & $142(19-213)$ & $<0.0001$ \\
\hline Brain natriuretic peptide, pg/mL, median (IQR) & $37(14-105)$ & $42(24-197)$ & $75(57-223)$ & 0.04 \\
\hline Lung crepitation, $n(\%)$ & $12(16)$ & $10(32)$ & $4(28)$ & 0.22 \\
\hline \multicolumn{5}{|l|}{ Baseline chest X-ray } \\
\hline Bilateral infiltrates, $n(\%)$ & $21(28)$ & $17(55)$ & $9(64)$ & 0.004 \\
\hline Lobar infiltrates, $n(\%)$ & $6(8)$ & $6(19)$ & $2(14)$ & 0.33 \\
\hline Pleural effusion, $n(\%)$ & $6(8)$ & $7(23)$ & $4(29)$ & 0.04 \\
\hline Hilar congestion, $n(\%)$ & $2(3)$ & $6(19)$ & $1(7)$ & 0.03 \\
\hline \multicolumn{5}{|l|}{ Baseline lung ultrasound } \\
\hline Pleural effusion, $n$ (\%) & $3(4)$ & $5(16)$ & $1(7)$ & 0.11 \\
\hline Homogenous diffuse B-lines, $n(\%)$ & $0(0)$ & $0(0)$ & $0(0)$ & NS \\
\hline Pleural thickening, $n(\%)$ & $57(73)$ & $30(97)$ & $13(93)$ & 0.009 \\
\hline Subpleural consolidations, $n(\%)$ & $53(71)$ & $27(87)$ & $13(93)$ & 0.04 \\
\hline Lung ultrasound score, median (IQR) & $12(5-18)$ & $19(14-22)$ & $23(16-28)$ & $<0.0001$ \\
\hline
\end{tabular}

a At the time of baseline lung ultrasound evaluation patients were stratified to mild disease (oxygen saturation $\geq 94 \%$ at room air) in 75 , moderate disease (need for non-invasive oxygen) in 31 and severe disease (need for mechanical ventilation) in 14

\section{Author details}

${ }^{1}$ Tel Aviv Sourasky Medical Center and Sackler School of Medicine, Tel Aviv University, Tel Aviv, Israel. ${ }^{2}$ Department of Cardiology, Tel Aviv Medical Center, Weizmann 6, 6423919 Tel Aviv, Israel.

\section{Publisher's Note}

Springer Nature remains neutral with regard to jurisdictional claims in published maps and institutional affiliations.

Published online: 25 September 2020 